\title{
Astronomia no Ensino Médio: uma abordagem simplificada a partir da Teoria da Relatividade Geral
}

\author{
Roberto Vinícios Lessa do Couto ${ }^{1}$, Marcello Ferreira², Olavo L. S. Filho ${ }^{3}$ \\ 1, 2, 3 Universidade de Brasília (UnB)
}

Palavras-Chave: Sequência Didática, Aprendizagem Significativa, Ausubel, Lipman, Astronomia.

\section{Introdução}

O estudo tem o objetivo pesquisar aportes da teoria da aprendizagem significativa de David Ausubel e do programa de filosofia para crianças e adolescentes de Matthew Lipman, para, a partir deles, delinear propostas de ensino de tópicos de astronomia ligados à gravitação clássica e à Relatividade Geral para o ensino médio.

Para tanto, pretende-se elaborar, aplicar e avaliar uma sequência didática abordando os seguintes tópicos de gravitação, em benefício do ensino de astronomia: breve histórico da gravitação, a lei da gravitação universal de Newton, o sistema solar, tópicos de relatividade restrita e geral, buracos negros e lentes gravitacionais. A aplicação da sequência didática se dará no contexto de uma turma do $3^{\circ}$ ano do ensino médio de uma escola pública do Distrito Federal.

\section{Metodologia}

A sequência didática foi construída tendo como base a aprendizagem significativa de Ausubel, que utiliza os conhecimentos prévios dos estudantes como âncora para que novos conhecimentos sejam introduzidos em sua estrutura cognitiva (MOREIRA, 2011), em conjunto com o programa de filosofia de Lipman, que tem o pensamento como seu elemento central e busca promover estratégias concretas visando atitudes críticas, reflexivas, criativas e autônomas por parte dos estudantes (FILHO; FERREIRA, 2018). Essa combinação de teorias é possível pelo fato de que a teoria de Ausubel tem caráter eminentemente descritivo, isto é, ela apresenta os elementos necessários para a ocorrência da aprendizagem, porém, de forma desconexa da realidade com que se dá essa aprendizagem (FILHO; FERREIRA, 2018). Para suprir essa lacuna, faz-se necessária uma teoria normativa que traduza o tipo de pessoa que se deseja formar; nesse caso, articula-se 0 programa de filosofia de Lipman.

Dentro desse contexto, a sequência didática foi dividida em cinco módulos, cada um apresentando aos estudantes tópicos de gravitação e astronomia, conforme descritos a seguir:

Módulo 1: breve histórico dos estudos sobre gravitação, descrevendo as contribuições de Aristóteles, Galileu, Newton e Einstein para o seu desenvolvimento.

Módulo 2: Lei da Gravitação Universal de Newton e o Sistema Solar.

Módulo 3: tópicos de relatividade restrita e geral como o espaço-tempo e como ele pode ser modificado.

Módulo 4: buracos negros, como são formados e quais suas principais características.

Módulo 5: lentes gravitacionais e como elas podem ser utilizadas como telescópios naturais.

Para discussão desses tópicos, serão utilizadas referências como D'Inverno (1992), Saa (2016) e outros na mesma linha, que apresentam seu formalismo e sua evolução histórica, além de outros aspectos importantes para melhor compreensão dos temas em estudo.

Os elementos da aprendizagem significativa constituem a parte estruturante da sequência didática. Seus elementos mais importantes - o que o estudante já sabe e sua disposição para aprender (MOREIRA, 2011) - permeiam toda a proposta.

Por exemplo, a matéria de ensino forma uma estrutura sequencial em que um módulo funciona como subsunçor do módulo subsequente. Um subsunçor é um conhecimento específico presente na estrutura cognitiva de um indivíduo, no qual um novo conhecimento ancora-se para a ocorrência da aprendizagem significativa (MOREIRA, 2011). Esse conhecimento pré-existente é o principal fator a influenciar a aprendizagem significativa. Nas palavras de Ausubel:

It follows from the very nature of accretion to the psychological structure of knowledge, through the assimilation process, that existing cognitive structure

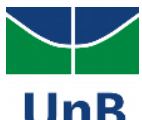


itself $[. .$.$] is the principal factor influencing meaningful learning and retention$ in this same field (AUSUBEL, 1968, p. 127).

Além disso, são propostas atividades diferenciadas, fugindo-se do padrão de aula expositiva, de modo a tentar manter a disposição do estudante para o aprendizado. Como exemplo, há uma atividade, no módulo dois, que utiliza um jogo/simulador em que é simulada a colisão de duas estrelas para ensinar a relação entre a massa de dois corpos e a força de interação entre eles.

Já os elementos do programa de filosofia de Lipman aparecem dentro das atividades em grupos, na forma das comunidades de investigação, por toda a sequência didática, como uma maneira de promover o diálogo entre os estudantes, mediado pelo professor. Uma comunidade de investigação é um ambiente no qual "[...] os alunos dividem opiniões com respeito, desenvolvem questões a partir das idéias de outros, desafiam-se entre si para fornecer razões e opiniões até então não apoiadas" (LIPMAN, 1995, p. 31).

Por exemplo, no módulo quatro, há uma atividade em que os estudantes são divididos em grupos para responderem a um questionário e, após, o professor media uma discussão entre esses eles para que possam confrontar suas respostas. Desse modo, pretende-se fazer com que os estudantes interajam entre si para complementarem suas respostas, articularem suas posições e promoverem juntos o conhecimento.

\section{Resultados Esperados}

Espera-se, dessa pesquisa, a produção de um material didático sobre astronomia, de aplicação factível em escolas públicas do país. Também se espera que esse material possa favorecer a aprendizagem significativa dos tópicos de gravitação e astronomia estudados, bem como que possa despertar nos estudantes a noção de que o conhecimento científico não está de todo estabelecido, mas que é fruto de um processo de construção longo, multifacetado e instável.

Os resultados apresentados são esperados uma vez que a pesquisa ainda encontra-se em fase de produção, com aplicação da sequência didática prevista para agosto de 2019. Entretanto, do ponto de vista da articulação teórica, a proposição já se mostra producente, uma vez que deriva de publicações científicas na área e que se organiza a partir de princípios estruturais consistentes. É previsível, portanto, que ela possa dar efetiva contribuição ao campo de pesquisa sobre aprendizagem significativa no ensino de física.

\section{Agradecimentos}

À Universidade de Brasília - UnB e à Sociedade Brasileira de Física - SBF, pela disponibilização do MNPEF. À Capes, pelo apoio financeiro.

\section{Referências}

AUSUBEL, D. Educational Psychology: a cognitive view. USA: Holt, Rinehart and Winston, Inc., 1968.

D'Inverno, R. A.; Introducing Einstein's Relativity. New York, Oxford University Press, 1992.

FILHO, O. L. S.; FERREIRA, M. Teorias da Aprendizagem e da Educação como Referenciais em Práticas de Ensino: Ausubel e Lipman. Revista do Professor de Física, v. 2, n. 2, p. 104-125, 2018.

LIPMAN, M. O Pensar na Educação. Petrópolis, RJ: Vozes, 1995.

MOREIRA, M. A. Teorias de Aprendizagem. 2ª ed. Ampliada. São Paulo: EPU, 2017. SAA, A. Cem anos de buracos negros: o centenário da solução de Schwarzchild. Revista

Brasileira de Ensino de Física, v. 38, n. 4, e4201, 2016. 